\title{
Sustainable Delivery Models for Achieving SDG7: Lessons from an Energy Services Social Enterprise in Malawi
}

\author{
Aran Eales \\ Electronic \& Electrical Engineering \\ University of Strathclyde \\ Glasgow, U.K. \\ aran.eales@strath.ac.uk \\ Edgar Bayani \\ Community Energy Malawi \\ Lilongwe, Malawi \\ edgarkbayani@gmail.com
}

\author{
Damien Frame \\ Electronic \& Electrical \\ Engineering \\ University of Strathclyde \\ Glasgow, U.K. \\ damien.frame@strath.ac.uk \\ Stuart Galloway \\ Electronic \& Electrical \\ Engineering \\ University of Strathclyde \\ Glasgow, U.K. \\ stuart.galloway.@strath.ac.uk
}

\author{
Will Coley \\ Electronic \& Electrical \\ Engineering \\ University of Strathclyde \\ Glasgow, U.K. \\ Will.coley@strath.ac.uk
}

Energy services social enterprises are emerging as a sustainable response to the challenges of achieving SDG 7, but detailed case study insight is lacking to inform the sector. Malawi has one of the lowest electricity access rates in the world, with a rural electrification rate of only $4 \%$. This paper highlights lessons from an energy service social enterprise in Malawi, using a case study framework to outline key achievements and challenges faced. The learning is used to form recommendations on increasing the impact, growth and sustainability of energy service social enterprises, both for grassroots practitioners as well as policy and investment decision makers. It has been found that energy service social enterprises need to develop robust strategies for sustainability through fostering cross sectoral linkages, investing in capacity building and awareness raising, collaborating through research partnerships, budgeting and resource planning conservatively, tracking social impact to inform business strategy, seeking innovation in business planning, and utilising smart subsidies. The case study analysis presented is intended to inform other social enterprises offering energy services, and to progress the rural electrification sector to achieve Sustainable Development Goal 7.

Keywords-social enterprise, energy access, Malawi

\section{INTRODUCTION}

\section{A. Energy Services Social Enterprises}

Recognising the need for innovative alternatives to status quo delivery models social enterprises have begun to fill in the gap between public and private provision of electricity to address energy poverty (1). The adoption of such models provide a market-based approach to addressing social issues that can provide business sources of revenue for civil society organizations (2)

Social enterprises exist within the third sector of the economy, addressing perceived shortcomings in government and market-based provision of social welfare, and are acknowledged as a potential driver of social progress (3). Several definitions for a social enterprise exist, including:
- "organisations who are independent of the state and provide services, goods and trade for a social purpose and are non-profit-distributing (4)"; and

- "a business with primarily social objectives whose surpluses are principally reinvested for that purpose in the business or in the community, rather than being driven by the need to maximise profits for shareholders and owners (5)".

The social enterprise business framework is therefore a potential enabler for sustainable development by balancing the three sustainability pillars in social, economic and environmental domains.

The concept of the 'energy delivery model' has emerged to describe a core set of activities and actors (constituting an energy service) that are required to make energy infrastructure sustainable (6). It highlights the importance of understanding how to fulfil end-users' needs as well as wider contextual considerations such as enabling-environment policies, additional supporting services and socio-cultural factors when designing and delivering energy services for low income communities. Traditionally, energy service delivery models have followed frameworks based on public, private, charity or hybrid models with varying degrees of success. The efficacy and sustainability of these approaches to reduce poverty through energy provision varies between models and has been questioned by stakeholders (7), (8), (9) (10). Within the 'energy for development' sector, delivery model innovation with a social focus has become a key means of embedding energy justice concepts in business models for energy provision (8).

Following the trends outlined above, there has been an associated proliferation of energy service companies that fulfil a social role, known collectively as 'energy services social enterprises'. Examples include D-light (11), Sunny Money (12), Devergy (13), PowerGen (14), RVE.SOL (15), and Standard Microgrid (16). Most focus on solar power provision although other renewable energy technologies (such as wind or hydro) and services (such as appliance finance) are offered.

In practical terms, there are a range of different configurations of what an energy service social enterprise 
looks like, ranging between a charitable entity looking to become financially self-sufficient, to private sector players responding to a social need with a market based approach. Furthermore, companies and charities are registered, regulated and audited in different ways, but from the perspective of an impact investor or funder there is not always a clear distinction between them.

Broadly, energy services social enterprises are private sector players offering products and services that aim to have a social impact either working in developing countries or serving difficult to reach populations. For example, Solar Aid (17) (a charity) has a non-profit social enterprise called Sunny Money (11) which provides pico-solar products (PSP) to remote communities in Africa, using a market based approach to solve a social problem. Some companies like D-light (10) have a wide product range incorporating low-priced products with tight margins which can provide affordable lighting for the poor, as well as more profitable higher-end products to support the business As such, it is clear that organisations in the energy access sector can be successful through applying strategies which are both profit-driven and have social aims. Providing energy services in remote areas of developing countries addresses multiple SDGs by enhancing socioeconomic wellbeing through improved quality of life, access to public services, job creation and entrepreneurship opportunities and industrialisation enabled by access to energy.

The efficacy of these services in achieving the challenge of SDG 7 specifically is largely dependent on the sustainability of the delivery model used to implement them. Private sector initiatives are showing promise to accelerate deployment of the nascent technology, but a purely profit driven approach is unlikely to deliver for the most vulnerable in society, hence only partially contributing to the SDGs. Governments in developing countries are by nature better suited to large infrastructure electrification programs but such rural electrification schemes have not so far provided universal access and have been unaffordable for most bottom-of-thepyramid (BoP) people (18). Furthermore, governments are generally ill-equipped with the business innovation expertise required for effective and impactful delivery, and as such, social enterprises, with social and environmental goals hardwritten into their constitutions, have high potential for delivering energy services with both increased social impact and increased sustainability, offering a robust mechanism to achieve SDG 7 in the Global South (19).

\section{B. Energy Access in Malawi}

Malawi has a rural electrification rate of only $4 \%$ and electricity use per capita of $85 \mathrm{kWh}$ (20). Grid electricity suffers from inadequate generation capacity and outdated transmission and distribution lines resulting in frequent blackouts and load shedding (21). In Malawi, distributed and renewable solutions are seen as essential to achieving 'energy for all' by 2030 (22). Supported by reductions in technology costs in recent years, solar PV solutions including PSP, kiosks and micro-grids are proving feasible for meeting lower tier electricity needs (23) (24) and are the focus of most off-grid energy projects in Malawi. Off grid solar PV installed capacity increased from 0.2 MW in 2007 to $10.4 \mathrm{MW}$ in 2016 (25) and sales of PSP is a growing market in Malawi, although currently less than $2.5 \%$ of households $(673,000$ people) own a PSP (26).
Innovative social business models that combine community-based approaches with entrepreneurship are demonstrating improved sustainability $(27,28)$ and have high potential for success in Malawi. Rural energy projects in Malawi have traditionally included aspects of community ownership and operation and targeted public facilities such as primary schools or health centres (29). Despite providing high short-term social impact, several of these projects have fallen short of sustainability expectations, typical of the historical experience with off-grid renewable energy projects in SSA (30). There appear to be few case studies of sustainable rural energy business models in Malawi with adequate capacity to operate and maintain the systems and the collection of tariffs enabling cost recovery of capital investment within a reasonable timeframe, as well as ongoing operation and maintenance costs. Across Malawi, repairs and maintenance capacity and the networks of expertise required to undertake and provide education and information on these vital systemic areas of work are lacking, thus creating a barrier to diffusion of off-grid energy technologies.

There are a number of energy services social enterprises operating in Malawi, including: Green Impact Technologies (31), FISD (32), MEGA (33), Kumudzi Kuwale (34), RECAPO (35), and Zuwa Energy (36) . All companies offer a variety of energy products and services including PSP, improved cook stoves, solar home systems (SHS) and more recently micro-grids. The energy services private sector is relatively nascent in Malawi and energy projects have been traditionally donor funded, however, an increase in private sector initiatives and focus has been evident over the last decade.

The remainder of this paper focusses on the case study of an emerging leader in the sustainable energy sector in Malawi: Community Energy Malawi (CEM), to draw out key learning on energy services social enterprises to inform the sector. Section II introduces the organisation's background and core activities, and describes the challenges CEM has experienced, grouped around the themes of technology, operations, capacity, the energy access ecosystem, funding mechanisms and networking. Section III goes on to translates these experiences and challenges into recommendations for the social enterprise energy access sector in Malawi. Conclusions for the wider social enterprise energy sector are brought out in Section IV.

\section{COMMUNity ENERGY MALAWI}

CEM is a social enterprise with a vision for "Affordable and Sustainable Energy for Malawian Communities"; it exists to help Malawian communities generate sustainable energy solutions to meet their energy needs. To realise this vision, CEM operates a three-year strategic plan with four strategic goals, namely of: transformative awareness; energy access for the last mile; active citizenship; civil society; and organisation sustainability. CEM has developed a social enterprise model which entailed having a subsidiary trading arm specifically to pursue energy access activities with commercial aims. CEM Trading was incorporated in 2016 as a wholly owned CEM Trust subsidiary.

\section{A. Background and Initiation}

In 2011 the Scottish Government commissioned a scoping study on supporting community energy development in Malawi (37). The outcomes of the study pointed to different 
programme activities that the Scottish Government might support. Those recommendations were taken forward in the form of the Malawi Renewable Energy Acceleration Programme (MREAP) (38). MREAP was managed by the University of Strathclyde and received $£ 2.3 \mathrm{~m}$ in funding, running from January 2012 to March 2015

Within MREAP, 46 individual community energy projects were developed and commissioned by Community Energy Scotland and CEM through the Community Energy Development Programme (CEDP), providing solar PV to offgrid schools and medical centres. The strand focused on community support with village energy committees to establish ownership for energy projects and revenue generating activities to pay for operation and maintenance. CEM Trading, private sector subsidiary of CEM, started in 2016 with distribution of solar lamps and SHS, following successful trials under CEDP.

\section{B. Review of Core Activities}

CEM's strategy is focused on creating sustainable, affordable and reliable energy services to remote communities in Malawi, reducing energy poverty and stimulating economic growth. Projects have involved implementation (e.g. getting solar PV installed or distributing PSP and improved cookstoves), and also research and advocacy to make changes in the energy ecosystem to shape the enabling environment to be more amenable to accelerated energy access through decentralised renewables. Key strategic themes have included: building on the foundations of CEDP, energy policy advocacy focussing on piloting the role of district energy officers and building sustainable revenue streams through diversification. The activities provide a basis on key learning to be drawn out to inform the energy services social enterprise sector in Malawi.

\section{1) Building on the foundations of CEDP}

A continual interest for CEM has been to ensure the systems installed under CEDP, and indeed all other renewable energy systems installed in Malawian communities, are sustainable, defined in this context as project sustainability in terms of technical, economic, social, and organisational themes. Through their experience implementing projects, CEM has found that key factors which compromise sustainability include a lack of qualified personnel in the communities to conduct maintenance and low knowledge levels and skills capacity in system operation and maintenance. Furthermore, the community energy model taken by MREAP and inherited by CEM needed to be evaluated to determine its effectiveness at creating sustainable projects and to determine any changes in the model which may be required. CEM has addressed these sustainability challenges by completing the following activities:

- Comprehensive sustainability studies of the systems (39-42) were carried out, covering all major pillars of sustainability relevant to this scale of renewable energy project (technical, economic, social, organisational, and environmental). With an existing data set in place (43 projects from the original study), the inclusion of CEM projects allowed for comparison and analysis of the project-level sustainability of the systems. This involved conducting a survey at each CEM location followed by analysis and production of the research output. Several refinements of the sustainability study methodology, based on learning from the original study, were included: creating a timeline of sustainability, removing weak sections of the survey, and transitioning to a digital field data gathering process.

- Training of local technicians in operation and maintenance of PV systems was carried out to address capacity gaps which are well recognised as limiting factors for the promotion of renewable energy in Malawi, also reducing the demand for CEM to provide costly maintenance services. Training encompassed system installation, troubleshooting, performance evaluation, panel re-alignment and power control amongst other technical subjects. The technicians were also trained in the maintenance of PSP, and technicians are currently under the supervision of CEM Trading who can provide remote technical support.

- Asset management strategies have been developed to ensure long-term sustainability of remote solar PV systems in Malawi, requiring effective strategies for managing fleets of off-grid infrastructure. Research was conducted into the operational status of the 82 solar PV battery systems that provide electricity to rural schools and health centres in Malawi. This was used to identify the challenges associated with administering and maintaining these systems over the first 5 years of the project's lifespan and provide recommendations for a more structured asset management approach. Suggestions include the collection of monthly servicing fees and specific operational measures to improve the long-term financial sustainability of the systems.

\section{2) Policy Engagement and Advocacy}

The increasingly decentralised nature of energy generation in SSA is occurring in an existing framework of decentralised governance (43). However, there has been a lack of focus on energy access issues within the various manifestations of decentralised governance (44). In Malawi, the proposed solution to address this gap is the introduction of District Energy Officers (DEOs). CEM was instrumental in the initial blueprinting of the role and remains key to the piloting of DEOs through continued collaboration with UK academics (45).

DEOs have subsequently been recognised as an enabler to accelerating energy access and the role has been adopted into official national policy (46). However, the implementation plan as well as roles and responsibilities of the DEOs are not yet fully defined. CEM staff have been engaged as interim DEOs in three districts (previously Lilongwe Rural, and now Balaka and Dedza), to investigate the tasks which the role would require including how DEOs would interact with existing district staff, community members and central government. The objective has been to develop a clear role description for a DEO with a clear proposal for implementing DEOs in each district across Malawi, delivered as a policy brief to the Government of Malawi (GoM) (45). In doing this, external frameworks and sources of support such as the SE4All Action agenda have been explored, and alongside the development of the policy brief, advocacy with GoM on the implementation of DEOs in all districts has continued. CEM continue to feed the results back to the GoM to inform the 
rollout of their DEO programme and the two parties have begun to map the proposed role and plan for its integration into local and national structures.

The DEO is envisaged as being an interlocutor between community level structures such as Village Development Committees, and national level authorities including the Malawi Energy Regulatory Authority (MERA). Thus, the DEO can identify energy regulatory matters that need to be reported to MERA from district level and beyond. Simultaneously, MERA can utilise the DEO to disseminate energy regulation matters at the district level and beyond. The position of DEO also permits further decentralisation of energy roles in the form of Energy Extension officers.

\section{3) Diversifying Revenue Streams}

To become a financially self-sufficient social enterprise and move from an NGO dependent on donor grants, establishing CEM Trading as a mechanism for independent income generation was a critical aspect of CEM's strategy. An early focus on the saturated and highly competitive PSP and SHS markets failed to generate substantial revenues for CEM Trading. Working with academic partners CEM built experience in market assessments and then conducted targeted feasibility studies of certain productive uses of energy (PUE) for identified communities (47). The market assessment work identified which PUE would be most viable from a community and a business perspective through surveys conducted with householders and business owners.

The results of the study informed the design of different pilot PUE projects deployed in Malawi in 2018, comprising: barbershop and phone charging; refrigeration in a village shop; shop lighting; TV and video; and an irrigation system. PUE pilot customers signed a multi-year Pay-As-You-Go (PAYG) contract to repay the cost of the systems in manageable increments over time. The repayment rates and financial performance of each PUE business were monitored to inform business model development for commercial opportunities for CEM Trading. In parallel, CEM and their partners engaged in a range of activities designed to learn from developments in other African countries; identifying the importance of mobile payment platforms for PAYG energy services and the rapid acceleration in deployment of solar PV minigrids.

A tailored capacity building programme then aimed to improve CEM's ability to lead in the adoption of these technologies in Malawi. As Malawi's policy support and regulatory framework for off-grid solutions strengthened, CEM Trading were uniquely positioned to partner with GoM and UNDP to deploy a pilot $80 \mathrm{~kW}$ solar PV minigrid, operating as a business in partnership with the local community. CEM Trading are now focussing on growing their asset base, seeking to own and operate off-grid energy assets. These assets will supply energy for both domestic and PUE paying customers.

The review of activities above describes CEM as an organisation emerging from a donor-funded project backed to a leading player in the energy sector in Malawi utilising established international partnerships. CEM have established a strong presence in the Malawian energy sector, fostering links with the Department of Energy Affairs and taking leading roles in strategy and policy development initiatives as well as developing a reputable Malawian led brand and progressing business activities of CEM Trading. Actively learning from prior work has been a feature of this progression.

\section{Key Experierential Learning}

This section, collated through project reports and discussions with CEM staff, draws out lessons from experiences on the challenges of running a social enterprise in Malawi and how they were overcome, categorised into specific themes. These lessons form the basis of the recommendations for the energy access sector given in Section III.

\section{a) Technology}

CEM's success has hinged upon its understanding and use of technology and innovation. Having a deep understanding of solar PV technology design, installation and maintenance has proven to be a key service offering. CEM's growth and success has hinged upon staff being aware of industry changes and new products.

In particular, due to the dispersed natural of off-grid energy assets and high cost of transport in Malawi, regularly gathering electricity demand data (for PUE or mini-grids) was a significant challenge. CEM has benefitted from staying abreast of developments in metering solutions for use in micro-grids, the use of data loggers to better understand load profiles of pilot productive uses of energy, and the newest PSP available on the market. Similarly good relationships with component suppliers both locally and internationally for PV system components and PSPs has been essential to the growth and efficiency of the organisation.

In addition, designing and implementing appropriate energy assets has required significant amounts of data gathering from a wide range of stakeholders (for example through feasibility studies and community engagement activities). The collation and analysis of such data through traditional paper-based methods would have been time consuming and error-prone. CEM has, with support from academic partners utilised smart phone technology for data capture and storage through the app Kobocollect (48), enabling remote data access and sharing through a cloudbased server. This use of innovative technology has increased efficiency of data collection and analysis, in turn bettering the understanding of customer needs and assessing the market. Collaborating with an academic institution for data analysis allows market and customer insight that CEM does not have time to undertake independently.

\section{b) Operations}

CEM have a Country Director who maintains a high profile and a strong network across the sector, as well as a team of Development Officers with a wide ranging skill set including market assessments, feasibility studies, renewable energy system sustainability assessment and planning, PUE, training and advocacy. The organisational set up of CEM Charity with subsidiary CEM Trading allows the organisation to respond actively and flexibly to a variety of funds and opportunities. However, CEM are still a small organisation experiencing limited growth, with heavy reliance on donor funding. A board of directors exists for strategic guidance but infrequent board meetings due to lack of funds has hindered effective progress in strategy planning. Despite the adoption of the above technologies, operating a business delivering services to remote communities continues to pose unique challenges, mostly due to the long distances involved and poor 
transport networks when reaching the customer communities. CEM have needed to have a presence in rural areas, but travel for fieldwork takes time and is costly.

Dissemination of CEMs achievements as well as holding an effective online presence and general media promotion was a challenge for CEM initially but since the recruitment of staff with relevant media skills this has been overcome, with CEM now regularly featuring in the national news and having a greatly improved online presence. These developments have had a direct impact on increased brand awareness fostering growth.

\section{c) Capacity}

In terms of local skills and capacity building, CEM staff have university degrees in renewable energy which has immensely benefitted the organisation. Additionally, staff have attended international training in the UK and Africa, as well as attending conferences such as IEEE's Power Africa (49) which allows for learning from other countries and builds the reputation of CEM at home and abroad.

The development of robust business plans have been slow and is still ongoing, assisted at times by funded local and international consultants. Guidance and support provided was useful, however, to be most effective the consultants need to spend time understanding the nuances and specifics of the organisation rather than providing generic advice, which limited funding has not always allowed. The recruitment of staff with business skills such as Finance Management and Marketing as well as technical skills in renewable energy system design and installation has been essential for CEM's growth. These additional staff represent a significant cost to already stretched budgets, however are paramount for the commercial elements of the social enterprise to take off.

\section{d) Energy Access Ecosystem}

Policy changes in Malawi's regulatory environment have been developing over the last few years. A delay in the release of the formal Malawi Energy Policy until November 2019 meant there was lack of clarity in the regulatory environment for CEM and this delay hindered decision making for businesses across the sector.

Malawi is a challenging environment to do business in, despite a large potential market for off-grid energy solutions due to $90 \%$ of its population being without access to electricity. A report by the Rocky Mountain Institute (50) observes that "mini-grids in Malawi are still expensive compared to regional benchmarks and depend on high levels of subsidy", highlighting why organisations like CEM fail to expand rapidly. There is generally low ability and willingness to pay for energy services in Malawi, making high-end energy services unaffordable which necessitates innovation in business models to be able to offer products at an affordable rate. When setting tariffs for micro-grids or prices for solar products, this low ability and willingness to pay has an effect on business income, necessitating subsidies to balance business costs with sufficient income. Malawi also has an unfavourable financing environment; there are high interest rates on loans and most investors see energy access projects as high risk with low returns (51). Lack of finance and capital is a challenge in any market, especially when selling renewable energy equipment where upfront costs are needed for purchasing system components and products.
However, the off-grid energy sector in Malawi is growing. Recent policy announcements provided a strong Government of Malawi commitment to delivering energy access targets through a combination of solutions, with decentralised, renewable energy being a major component. Malawi has a lack of local organisations with knowledge and skills to deliver sustainable off-grid energy projects. This presents a challenge to the delivery of Government of Malawi policies such as targeting 50 clean energy mini-grid deployments by 2025 (46). There are few Malawian based organisations with the capacity to deploy mini-grid projects as a business activity. CEM Trading are well positioned to develop their offering as an energy provider and asset manager, identifying appropriate business models to deploy micro-grid assets in partnership with local communities.

\section{e) Funding Mechanisms}

It is clear that grants or donor funding have been essential in the early stages of CEMs development, used to cushion the formative years of the social enterprise while developing a long term goal of becoming a self-sustaining business entity. A key challenge faced has been to streamline the transition from donor funding to financial self-sufficiency through income from the commercial arm of the organisation CEM Trading. As a small organisation CEM has difficulties in dealing with funding delays due to administrative hurdles or bottlenecks on all sides. Short-term funding gaps have sometimes caused delays in salary payments, reducing staff morale and decreasing chances of retaining key human resource. Longer term funding gaps, or inability to secure long-term funds has also had a negative effect on staff retention.

Support from donor funding is essential for the survival of early stage organisations, however dependency on donor funding has the potential to stymy the move to private sector independence, and fulfilling donor obligations can take resources away from where they are most needed, limiting growth and stifling innovation. A noted general threat to CEM is the breadth of activity and funding opportunity currently available in Malawi resulting in a lack of focus and an overreach of commitments that the organisation struggles to support.

\section{f) Networking}

CEM has shown excellent ability to network with other players in the energy sector in Malawi, and the benefits of such cross sector linkages are evidenced through joint funding applications and the increased brand awareness of CEM in Malawi. As mentioned previously, CEM is well connected to the Department of Energy Affairs, allowing a direct route to advocacy on energy access matters; essential for the impact of their DEO work. Internationally, CEM have maintained strong relationships with academia, third sector and private sector energy players and have successfully independently bid for international funding opportunities including from the Scottish Government and IEEE. The decentralised renewable energy sector is accelerating across Sub Saharan Africa, and there are numerous start-ups operating in Kenya, Rwanda, Tanzania and Zambia that may see Malawi as the next market opportunity. Additionally, other local players have already started to respond to the off-grid market opportunity, especially SHS suppliers. Collaboration and shared learning with such players will be pivotal to CEM's growth, although these organisations also pose a competitive threat. 


\section{RECOMMENDATIONS FOR THE SECTOR}

Previous sections have highlighted key lessons from an energy services social enterprise in Malawi through a case study evaluation. The experiential learning has demonstrated that social enterprises can play a key role in accelerating energy access in Malawi. However, several challenges and barriers have been shown to achieving growth and organisational sustainability. Accordingly, the following section makes recommendations to increase the impact, growth and sustainability of energy service social enterprises. Recommendations are based on, and linked to, the findings of this case study, and are provided both for practitioners working on the front line of energy service delivery to remote communities as well as decision makers in investment or policy.

\section{A. Strategies for Sustainability}

Long-term strategies are needed that are not only responsive to the funding available but achieve resilience through maintaining income from products and services. The case study demonstrated that CEM has at times followed the former due to a necessity to respond to opportunities in a fluid and rapidly evolving sector but through focused strategizing, are transitioning towards longer term goals with enhanced focus on sustainability.

\section{B. Cross Sectoral Linkages}

Social enterprises should embed themselves in a network with organisations focussing on energy access at all levels including NGOs, government, private sector and research institutions, be part of actor networks as well as coordinate stakeholder interactions. CEM's growth would not have been possible without their active engagement with academia, business and civil society.

\section{Capacity Building}

Underpinning successful operation and growth lies effective organisational capacity and an identified need for ongoing capacity building and development of human resources. Local capacity building needs to be prioritised for effective social enterprises to function and grow sustainably, with a budget required to support interventions. The recruitment of well-trained staff and ongoing skill development through mentoring and international courses has been integral to CEM delivering quality outputs for funders and growing their organisation.

\section{Conservative Budgeting and Resource Planning}

Social enterprises are often working at the front line of emerging markets in challenging environments and economies. There are associated high levels of cost in terms of time and money to get their businesses off the ground, including higher customer acquisition costs for reaching remote areas geographically, or increased need for consumer awareness and trust building. These increased costs need to be accounted for and budgeted accordingly with support from patient capital or donor funding aligned with the objectives of the social enterprise. Detailed and prudent financial planning has been core to CEM on a project by project basis, as well as forecasting resource requirements for growth.

\section{E. Research Partnerships}

Collaborating with academic institutions for data analysis allows much needed insight into customer behaviour and market opportunities which facilitates more effective project design. A symbiotic opportunity is offered as universities gain experience and research outputs while the social enterprise, often not having time or resources to undertake such research, receives data analysis and recommendations for improved services. CEM's ongoing partnership with academia in Malawi and the UK has produced collaborative reports on market assessments, social impact and policy recommendations, valuable for both CEM's strategic goals as well as informing the energy sector as a whole.

\section{F. Understanding Customers}

For poor, dispersed rural communities electricity supply is often not enough. Projects must be designed to be run as businesses with livelihoods components to increase community income built in, rather than assumed to evolve from the provision of electricity. Social enterprises need to understand the needs of base of pyramid customers and be able to serve them in an efficient way. CEM's use of surveys to understand customer needs and responding through innovative delivery models has been a pivotal organisational focus.

\section{G. Awareness Raising}

Social enterprises have a role to play in raising awareness and delivering accurate information. Those in the energy services sector should be trained in product knowledge to advise on the quality of products to help communities make decisions on economic uses of distributed, solar-generated electricity. Through the CEDP project and subsequent PSP distribution programmes, the strong focus CEM has placed on community engagement, education and awareness raising has been paramount to successful product uptake and acceptance in communities.

\section{H. Understanding Technology}

Technical innovations for decentralised renewable energy technologies including smart metering, data logging, remote monitoring and control should be utilised by energy services social enterprises in order for them to flourish. Efforts should be made to explore supply chain options for such technology, as well as developing opportunities for local manufacture to increase the local value chain elements, spurring economic development. The case study has demonstrated CEM's ability to utilise cutting edge technology in metering, datalogging, and PV system components to further its social and economic aims.

\section{Impact Measurement}

Social impact measurement should be conducted to inform business strategy, but also shared with government and other energy sector players to make better informed decisions on resource allocations and have better understanding of how project design of local solar PV services affects social impact on customers. CEM's policy engagement through DEOs has clearly demonstrated the utility of well-informed policy based on social impact quantification and monitoring with respect to SDG 7.

\section{J. Innovation in business planning}

More research is required to develop and trial social enterprise models, linked with innovative financing mechanisms. Innovation is also key regarding community engagement to ensure community dynamics are well handled. Business model innovation can include diversification of income sources such as facilitating development of start-ups 
and businesses in communities served and even co-owning some of the downstream businesses. For example, CEM has plans to help dairy farmers in the village served by their microgrid form a dairy cooperative. By leveraging its profile, CEM will set up a milk cooling or processing plant and coown that business with the dairy cooperative. This will not only increase demand for electricity (thus increasing tariff income), but also diversify their revenue streams.

\section{K. Smart Subsidies}

Policy makers should create smart subsidies which don't distort the market, focussing on social enterprises to address those living in extreme poverty through facilitating the offering of products and services to those who would otherwise be unable to afford them. Governments should be supporting social enterprises to connect the final customers, opportunities CEM will be pursuing through its continued engagement with the Government of Malawi Department of Energy Affairs.

\section{CONCLUSIONS}

Energy services social enterprises are working on the front lines of innovation in developing countries and in emerging markets, building trust and awareness around new technologies; while some barriers remain, they are emerging as a sustainable response to the challenges of achieving SDG 7. To succeed, skills in innovation and entrepreneurship are needed within energy services social enterprises, as well as effective support from the energy sector's enabling environment.

This paper has highlighted challenges and opportunities for energy service social enterprises through a case study evaluation of Community Energy Malawi. It has shown how regulatory and organisational features, partnerships and a clear strategic goal are important for the delivery of a sustainable outcome. Recommendations have been given to increase the impact, growth and sustainability of energy service social enterprises, both for practitioners working on the front line of offering energy access to remote communities as well as decision makers in investment or policy to accelerate access to energy through more efficient and sustainable delivery models. These recommendations span a wide variety of sectors, stakeholders and approaches, which if adopted will help to improve access to energy for all in a way which is both economically and environmentally sound as well as beneficial to those at all levels of society.

\section{REFERENCES}

1. Warnecke T, Houndonougbo AN. Let There Be Light: Social Enterprise, Solar Power, and Sustainable Development. 2016 [cited 2018 Jul 24]; Available from: http://www.tandfonline.com/action/journalInformation?journalCo de $=$ mjei20

2. Kerlin JA. Defining Social Enterprise Across Different Contexts. Nonprofit Volunt Sect Q [Internet]. 2013 Feb 13 [cited 2019 Apr 12];42(1):84-108. Available from: http://journals.sagepub.com/doi/10.1177/0899764011433040

3. Scottish Government. Scotland's Social Enterprise Strategy 2016$2026 \quad$ [Internet]. 2016. Available from: https:/www.gov.scot/binaries/content/documents/govscot/publica tions/strategy-plan/2016/12/scotlands-social-enterprise-strategy2016-2026/documents/00511500-pdf/00511500-

\section{pdf/govscot $\% 3$ Adocument}

4. Social enterprise action plan Scaling new heights [Internet]. [cited 2019 Apr 11]. Available from: https://webarchive.nationalarchives.gov.uk/20070101085548/http ://www.cabinetoffice.gov.uk/third_sector/documents/social_enter prise/se_action_plan_2006.pdf

5. Department of Trade and Industry. SOCIAL ENTERPRISE: A STRATEGY FOR SUCCESS [Internet]. 2002 [cited 2019 Apr 11].

Available from: http://www.publicnet.co.uk/abstracts/2003/10/23/socialenterprise-a-strategy-for-success/

6. Garside B, Wykes S. Planning pro-poor energy services for maximum impact: the energy delivery model toolkit. 2017; Available from: www.alexquero.co.uk

7. Sovacool BK. The political economy of energy poverty: A review of key challenges. Energy Sustain Dev [Internet]. 2012 Sep 1 [cited 2019 Apr 12];16(3):272-82. Available from: https://www.sciencedirect.com/science/article/pii/S09730826120 00373

8. Hiteva R, Sovacool B. Harnessing Social Innovation for Energy Justice: A Business Model Perspective "EXPLORING THE ENERGY JUSTICE NEXUS" Special Edition in Energy Policy [Internet]. [cited 2019 Apr 11]. Available from: https://core.ac.uk/download/pdf/82915040.pdf

9. Newell P, Frynas JG. Beyond csr? Business, poverty and social justice: an introduction. Third World Q [Internet]. 2007 Jun [cited 2019 Apr 12];28(4):669-81. Available from: http://www.tandfonline.com/doi/abs/10.1080/0143659070133650 7

10. Scott L, McGill A. From promise to reality: Does business really care about the SDGs? [Internet]. 2018 [cited 2019 Apr 9]. Available from: www.pwc.com/sdgreportingchallenge

11. Solar LED Lanterns and Off Grid Solar System Company - d.light [Internet]. [cited 2020 Jun 12]. Available from: https://www.dlight.com/

12. Home / SunnyMoney - Life is Getting Brighter [Internet]. [cited 2020 Jun 12]. Available from: https://www.sunnymoney.org/

13. Devergy | Home - devergy [Internet]. [cited 2020 Jun 12]. Available from: https://devergy.com/

14. PowerGen Renewable Energy - Africa's Power Future [Internet]. [cited 2018 May 2]. Available from: http://www.powergenrenewable-energy.com/

15. RVE.SOL | Changing Rural Life Forever | Changing Rural Life Forever [Internet]. [cited 2020 Jun 12]. Available from: https://www.rvesol.com/

16. Reimagining Power | Standard Microgrid [Internet]. [cited 2020 Jun 12]. Available from: https://standardmicrogrid.com/

17. Home - SolarAid [Internet]. [cited 2020 Jun 14]. Available from: https://solar-aid.org/

18. Bhattacharyya SC, Palit D. Mini-grid based off-grid electrification to enhance electricity access in developing countries: What policies may be required? Energy Policy. 2016 Jul 1;94:166-78.

19. Eales A, Strachan S, Frame D, Galloway S. Assessing the feasibility of solar microgrid social enterprises as an appropriate delivery model for achieving SDG7. 2019. 
Access to electricity (\% of population) | Data [Internet]. [cited 2019 Dec 4]. Available from: https://data.worldbank.org/indicator/EG.ELC.ACCS.ZS

21. (No Title) [Internet]. [cited 2020 Jun 14]. Available from: http://documents.worldbank.org/curated/en/52077156134171579 2/pdf/Malawi-Electricity-Access-Project.pdf

22 - International Energy Agency I. WEO-2017 Special Report: Energy Access Outlook [Internet]. 2030 [cited 2019 Apr 29]. Available from: www.iea.org/t\&c/

23. Multi-Tier Framework for Measuring Energy Access | ESMAP [Internet]. [cited 2018 Mar 28]. Available from: https://www.esmap.org/node/55526

24. Roche OM, Blanchard RE. Design of a solar energy centre for providing lighting and income-generating activities for off-grid rural communities in Kenya. Renew Energy. 2018 Apr 1;118:68594.

25. Renewable Energy Agency I. SOLAR PV IN AFRICA: COSTS AND MARKETS. 2016 [cited 2017 Aug 4]; Available from: https://www.irena.org/DocumentDownloads/Publications/IRENA _Solar_PV_Costs_Africa_2016.pdf

26. BIF. BIF2 Malawi: Pico Solar Products (PSP) Market Analysis and Strategy. 2014 [cited 2017 Aug 21]; Available from: http://conrema.org/sites/default/files/PSP Market Analysis and Strategy BIF Malawi May 2014_compressed.pdf

27. Munro P, van der Horst G, Willans S, Kemeny P, Christiansen A, Schiavone N. Social enterprise development and renewable energy dissemination in Africa: The experience of the community charging station model in Sierra Leone. Prog Dev Stud [Internet]. 2016 Jan 17 [cited 2019 Apr 29];16(1):24-38. Available from: http://journals.sagepub.com/doi/10.1177/1464993415608080

28. Katre A, Tozzi A, Bhattacharyya S. Sustainability of communityowned mini-grids: evidence from India. Energy Sustain Soc [Internet]. 2019 Dec 21 [cited 2019 Apr 29];9(1):2. Available from:

https://energsustainsoc.springeropen.com/articles/10.1186/s13705 $-018-0185-9$

29. Dauenhauer PM, Frame DF. Critical review of the Malawi community energy model. In: 2016 IEEE PES PowerAfrica [Internet]. IEEE; 2016 [cited 2017 Aug 28]. p. 78-82. Available from: http://ieeexplore.ieee.org/document/7556575/

30. Chaurey A, Krithika PR, Palit D, Rakesh S, Sovacool BK. New partnerships and business models for facilitating energy access. 2012 [cited 2019 Apr 29]; Available from: http://dx.doi.org/10.1016/j.enpol.2012.03.031

31. Green Impact Technologies Malawi,solar,energy [Internet]. [cited 2020 Jun 14]. Available from: https:/www.greenimpacttech.org/ FISD COMPANY LTD [Internet]. [cited 2020 Jun 14]. Available from: https://www.fisdltd.com/

33. Home | MEGA [Internet]. [cited 2018 Mar 28]. Available from: http://www.mega.mw/

34. Kumudzi Kuwale [Internet]. [cited 2020 Jun 14]. Available from: https://www.kumudzikuwale.com/

35. About RECAPO Solar [Internet]. [cited 2020 Jun 14]. Available from: http://www.recaposolar.com/about-us.html

36. Zuwa - Energy - Prepaid, Affordable And Reliable Solar Electricity! [Internet]. [cited 2020 Jun 14]. Available from: http://zuwaenergymw.com/

37. Davis G, MacKay R, MacRae M, Nicolson L, Currie C, MacPherson R, et al. Supporting community energy development in Malawi : a scoping study for the Scottish Government. 2011 Aug 31 ;

38. Malawi Renewable Energy Acceleration Programme | University of Strathclyde [Internet]. [cited 2020 Jun 14]. Available from: https://www.strath.ac.uk/engineering/electronicelectricalengineeri ng/ourinternationalprogrammesprojects/malawirenewableenergya ccelerationprogramme/

39. Buckland H, Frame D, Dauenhauer P, Eales A, Strachan S. Sustainability of Solar PV Institutions in Malawi. University of Strathclyde; 2015.

40. Frame D, Dauenhauer P. Sustainability of Solar PV Institutions in Malawi. [cited 2017 Aug 28]; Available from: http://www.strath.ac.uk/eee/energymalawi/

41. Breuer H, Lüdeke-Freund F. Values-Based Business Model Innovation: A Toolkit. 2018;395-416.

42. Peter Dauenhauer, Damien Frame A, Eales, Scott Strachan SG, Buckland and H. Sustainability Evaluation of Community-Based, Solar Photovoltaic Projects in Malawi. Energy Sustain Soc. 2019;

43. Mohmand SK, Loureiro M. Introduction: Interrogating decentralisation in Africa. IDS Bull. 2017 Mar 1;48(2):1-14.

44. Zalengera C, To LS, Sieff R, Mohr A, Eales A, Cloke J, et al. Decentralization: the key to accelerating access to distributed energy services in sub-Saharan Africa? J Environ Stud Sci. 2020 May 5;

45. Buckland H, Eales A, Brown E, Cloke J, Blanchard R, Yona L, et al. Malawi District Energy Officer Blueprint: Recommendations Paper [Internet]. 2017 [cited 2018 Apr 4]. Available from: https://pure.strath.ac.uk/portal/en/publications/malawi-districtenergy-officer-blueprint(bd5a94cf-68a2-434a-b11acb98de6da4b4).html

46. Malawi $\mathrm{G}$ of. MALAWI NATIONAL ENERGY POLICY [Internet]. 2018. Available from: https://energy.gov.mw/index.php/resource-

centre/documents/policies-strategies?download=15:energy-policy

47. Eales A, Buckland H, Frame D, Unyolo B, Gondwe C, Kaunda M. Productive Use of Solar PV in Rural Malawi: Feasibility Studies [Internet]. University of Strathclyde; 2017 [cited 2019 Apr 11]. Available from: https://pureportal.strath.ac.uk/en/publications/productive-use-ofsolar-pv-in-rural-malawi-feasibility-studies

48. KoBoToolbox | Data Collection Tools for Challenging Environments [Internet]. [cited 2018 Apr 3]. Available from: http://www.kobotoolbox.org/

49. Homepage - IEEE PowerAfrica Conference 2020 [Internet]. [cited 2020 Jun 14]. Available from: https://ieee-powerafrica.org/

50. Malawi Sustainable Energy Investment Study DRAFT FOR VALIDATION WORKSHOP GOVERNMENT OF MALAWI Ministry of Natural Resources, Energy and Mining. 2019.

51. Eales A, Unyolo B. Renewable Energy Mini-grids in Malawi: Status, Barriers and Opportunities. University of Strathclyde, editor. Scottish Government; 2018. 